\title{
Understanding Cardiac Rehabilitation
}

\author{
Tsaloglidou $A^{* 1}$, Koukourikos $\mathbf{K}^{1}$, Frantzana Aik ${ }^{2}$ and Kourkouta $\mathrm{L}^{1}$ \\ ${ }^{1}$ Nursing Department, International Hellenic University, Greece \\ ${ }^{2}$ Department of Health Sciences, European University of Cyprus, Greece
}

*Corresponding author: Aikaterini Frantzana, Department of Health Sciences, European University of Cyprus, Greece.

To Cite This Article: Tsaloglidou A. Understanding Cardiac Rehabilitation. Am J Biomed Sci \& Res. 2019 - 4(6). AJBSR.MS.ID.000851. DOI: 10.34297/ AJBSR.2019.04.000851

Received: 眥 August 19, 2019; Published: 眥 August 26, 2019

\begin{abstract}
Introduction: Cardiovascular disease remains the most frequent cause of death globally. Patients with coronary heart disease (CHD) who have experienced an acute myocardial infarction (AMI) or have undergone cardiac surgery are prime candidates for applying to cardiac rehabilitation programs. Cardiac rehabilitation is a multidisciplinary, systemic approach to implementing secondary prevention therapies of known beneficial effects.
\end{abstract}

Purpose: The purpose of this review study is to investigate the contribution of cardiac rehabilitation programs in improving patients' cardiovascular health and enhancing their quality of life after an incidence of acute myocardial infarction or after a cardiac surgery.

Methodology: An Extensive review of the relevant literature was performed via electronic databases (Medline, Scopus and Google Scholar) and international scientific journals, using the appropriate key words: cardiac rehabilitation program, myocardial infarction, cardiac surgery and a combination of them.

Results: All cardiac rehabilitation programs should contain specific key components aimed at optimizing cardiovascular risk reduction, encouraging healthy behaviors and compliance with these behaviors, reducing disability, and promoting an active lifestyle for patients with cardiovascular disease. The components of cardiac rehabilitation programs are staffed by a highly skilled team comprising a medical director, cardiac care registered nurses, exercise specialists, dietitian, and counselors. These programs include provision of comprehensive long-term services involving the following key elements: basic patient assessment, nutritional counseling, risk factor management (lipids, blood pressure, weight, diabetes mellitus, and smoking), psychosocial interventions, physical activity counseling and exercise training

Conclusions: Cardiac rehabilitation is a complex intervention offered to patients after myocardial infarction or cardiac surgery to achieve professionally recommended cardiovascular prevention targets and thus good clinical status leading to improved patient's quality of life. Despite the beneficial effects of cardiac rehabilitation, the overall participation rates remain low due to absent or inadequate legislation, funding, professional guidelines and information systems in many countries, as well as patient related barriers.

\section{Introduction}

Cardiovascular disease remains the most frequent cause of death globally. Patients with coronary heart disease (CHD) who have experienced an acute myocardial infarction (AMI) or have undergone cardiac surgery are prime candidates for applying to cardiac rehabilitation programs [1]. All types of cardiac surgery almost include some steps before, during and mainly after the surgery. Interventions such as coronary bypass, valve replacement, congenital abnormality correction, and some interventions for cardiomyopathy and pericarditis have common features. Cardiac rehabilitation is an important part of the recovery process from all the pre-mentioned events. In 1967, the World Health Organization defined rehabilitation as the set of actions needed to enable persons with disabilities to attain and maintain their maximum independence, full physical, mental, social and vocational ability, and full inclusion and participation in all aspects of life [2]. Cardiac rehabilitation is a multidisciplinary, systemic approach to implementing secondary prevention therapies of known beneficial effects [3]. American College of Cardiology guidelines emphasize the importance of cardiac rehabilitation as a vehicle to achieve necessary lifestyle modifications after a cardiac event $[4,5]$. The rehabilitation process for cardiac patients begins with patients entering the hospital and continues for the rest of their lives.

\section{Cardiac Rehabilitation Programs}

Cardiac Rehabilitation programs are medically supervised programs designed to help the patients improve their cardiovascular health and enhance their quality of life after an incidence of acute myocardial infarction or after a cardiac surgery. 
It is well established in the literature that they reduce mortality by $20-25 \%$. These benefits are similar in magnitude to those resulting from the administration of major cardiac medications or from a cardiac surgery [6,7]. All cardiac rehabilitation programs should contain specific key components aimed at optimizing cardiovascular risk reduction, encouraging healthy behaviors and compliance with these behaviors, reducing disability, and promoting an active lifestyle for patients with cardiovascular disease [8]. The components of cardiac rehabilitation programs are staffed by a highly skilled team comprising a medical director, cardiac care registered nurses, exercise specialists, dietitian, and counselors. These programs include provision of comprehensive long-term services involving the following key elements $[9,10]$ : basic patient assessment, nutritional counseling, risk factor management (lipids, blood pressure, weight, diabetes mellitus, and smoking), psychosocial interventions, physical activity counseling and exercise training [11].

\section{Cardiac Rehabilitation Phases}

Cardiac Rehabilitation has been conventionally divided into four phases [12].

i. Phase I known as the hospital phase, aims to minimize the negative effects of restriction to bed and ends with the patient leaving the hospital [13]. The recommendations of American College of Sports Medicine (ACSM) for the intensity in phase-1 CR among post MI patients include, training the patient up to a heart rate of 120 beats/minute, guided by symptoms of chest pain and interval training with bouts of exercises lasting from three to five minutes or as tolerated, interspersed with adequate rest periods in order to achieve an exercise/rest ratio of 2:1. After an acute coronary event, Phase 1 Cardiac Rehabilitation is important to help the patient's recovering. It consists of medical assessment, assurance and training on $\mathrm{CAD}$, correction of cardiac misconceptions, assessment of risk factors and early mobilization of the patient [14].

ii. Phase II (up to $12 \mathrm{wk}$ ) is the phase immediately following discharge from hospital and involves continued monitoring of patient's cardiac responses to exercise and activity. It is known as the early out-patient phase and aims to gradually increasing exercise tolerance [13]. As such, it may include, treadmill exercise testing, exercise training, inspiratory muscle training, as well as education about proper exercise procedures for the patient to return safely to functional mobility while monitoring of his heart rate. The main benefits of Phase II are that it decreases the chance of another cardiac event, stops or reverse blood vessels damage, improves patient's stamina, confidence and wellbeing. It also controls heart disease symptoms such as chest pain or shortness of air $[15,16]$. It has been well demonstrated in the literature that short-term inspiratory muscle training (IMT) programs combined with aerobic and resistance training in patients undergoing phase II, after CABG or other cardiac surgery, lead to large increments in respiratory muscle strength, functional capacity, and quality of life [17].

iii. Phase III of Cardiac rehabilitation, known as the late outpatient phase (variable duration) typically includes an outpatient program aiming at developing exercises with more intensity [13]. Key elements of phase III are exercise training, education, psychological support and risk factor modification. Most phase III programs involve supervised exercise training once or twice per week in a hospital setting or in community or home-based setting. The exercise training at this phase includes six-minutes' walk test, timed up and go test, biking, rowing, exercises to increase flexibility, upper body strength and lower body strength. The goal for the patient at this stage is to become independent enough to move safely to the last phase of his recovery program [18].

iv. The fourth and final phase is often referred as preventive or maintenance phase of cardiac rehabilitation, as it emphasizes longterm lifestyle changes, such as a regular exercise program, healthy diet, healthy weight, anti- smoking behavior and dealing with stress. It seems to improve cardiorespiratory fitness, hemodynamics at peak exercise and heart rate recovery, an indicator of cardiac autonomic function. This phase should have a starting date but not a finishing one, as it focuses on making lifestyle changes part of everyday life. Regular communication with the rehabilitation team for periodic reviews and assessments is an important part of phase IV [19]. Cardiac rehabilitation programs are based on longestablished models involving residential or ambulatory programs and differ between them according to local and national guidelines [20].

\section{Barriers to Cardiac Rehabilitation}

Despite the documented evidence of the benefits of cardiac rehabilitation programs in enhancing recovery, improving survival, improving exercise capacity, reducing mortality following a myocardial infarction or a cardiac surgery and decreasing the risk of recurrent MI, only about one third of patients participate in such programs. Several clinical and psychosocial factors are associated with decreased participation in cardiac rehabilitation programs [21,22]. Many potential barriers to participation in cardiac rehabilitation have been assessed in the literature including patient-level factors, such as the lack of insurance coverage or multiple co-morbidities. Lack of physician recommendation, lack of awareness of cardiac rehabilitation indications among providers, and lower education are also main barriers to the participation to CR programs.

Psychosocial barriers have also been identified including depression, social deprivation and lower socioeconomic status. Furthermore, lack of transportation, lack of motivation, reduced self-efficacy, and perception that rehabilitation is inconvenient or unnecessary are also referred as main obstacles [23-26]. Women are significantly less likely to participate in and complete cardiac 
rehabilitation programs. The reasons of why women are missing from CR programs are multi-factorial. Older women express a dissatisfaction regarding mixed sex exercise groups, and they are worried about inability to maintain their household obligations, while younger women are staying away from CR programs because they believe that rehabilitation is only for older adults [27].

\section{Conclusions}

Cardiac rehabilitation is a complex intervention offered to patients after myocardial infarction or cardiac surgery to achieve professionally recommended cardiovascular prevention targets and thus good clinical status leading to improved patient's quality of life. Cardiac rehabilitation includes health education, psychological counseling, risk factors modification, physical activity, dietary advice and stress management. Despite the beneficial effects of cardiac rehabilitation, through effective lifestyle and cardiac riskfactor management, the overall participation rates are low due to absent or inadequate legislation, funding, professional guidelines and information systems in many countries as well as patient related barriers.

\section{References}

1. Suaya JA, Shepard DS, Normand SLT, Ades PA, Prottas J, et al. (2007) Use of Cardiac Rehabilitation by Medicare Beneficiaries After Myocardial Infarction or Coronary Bypass Surgery. Circulation 116(15): 1653-1662.

2. WHO (2011) World Bank World report on disability, Chapter 4 on disability? pp. 1-350.

3. Brandi JW, Steven JJ, Weston SA, Killian JM, Meverden RA, et al. (2004) Cardiac rehabilitation after myocardial infarction in the community. J Am Coll Cardiol 44(5): 988-996.

4. Mosca L, Appel LJ, Benjamin EJ, Berra K, Chandra Strobos N (2004) Evidence-based guidelines for cardiovascular disease prevention in women. Circulation 109: 672-692.

5. Thomas RJ, Balady G, Banka G, Beckie TM, Chiu J, et al. (2018) ACC/AHA Clinical Performance and Quality Measures for Cardiac Rehabilititation: A Report of the American College of Cardiology/American Heart Association Task Force on Performance Measures. J Am Coll Cardiol 71(16): 1814-1837.

6. Jackson L, Leclerc J, Erskine Y, Linden W (2005) Getting the most out of cardiac rehabilitation: a review of referral and adherence predictors. Heart 91(1): 10-14.

7. Lau J, Antman EM, Jimenez Silva J, Kupelnick B, Mosteller F, et al. (2002) Cumulative meta-analysis of therapeutic trials for myocardial infarction. N Engl J Med 327(4): 248-254.

8. Balady GJ, Ades PA, Comoss P, Limacher M, Piña IL, et al. (2000) Core components of cardiac rehabilitation/secondary prevention programs: a statement for healthcare professionals from the American Heart Association and the American Association of Cardiovascular and Pulmonary Rehabilitation Writing Group. Circulation 102(9): 1069-1073.

9. Wenger NK (2008) Current status of cardiac rehabilitation. J Am Coll Cardiol 51(17): 1619-1631.

10. Balady GJ, Wiliams MA, Ades PA, Bittner V, Comoss P, et al. (2007) Core components of cardiac rehabilitation/secondary prevention programs: 2007 update: a scientific statement from the American Heart Association Exercise, Cardiac Rehabilitation, and Prevention Committee, the Council on Clinical Cardiology; the Councils on Cardiovascular Nursing,
Epidemiology and Prevention, and Nutrition, Physical Activity and Metabolism and the American Association of Cardiovascular and Pulmonary Rehabilitation. Circulation 115(20): 2675-2682.

11. Smith SC, Allen J, Blair SN, Bonow RO, Brass LM, et al. (2006) AHA/ACC guidelines for secondary prevention for patients with coronary and other atherosclerotic vascular disease: 2006 update: endorsed by the $\mathrm{Na}$ tional Heart, Lung, and Blood Institute. Circulation 113(19): 2363-2372.

12. (2002) Cardiac Rehabilitation, no. 57 Edinburgh. Scottish Intercollegiate Guidelines Network (SIGN): p. 1-2.

13. Leon AS, Franklin BA, Costa F, Balady GJ, Berra KA, et al. (2005) Cardiac rehabilitation and secondary prevention of coronary heart disease: an American Heart Association scientific statement from the Council on Clinical Cardiology (Subcommittee on Exercise, Cardiac Rehabilitation and Prevention) and the Council on Nutrition, Physical Activity, and Metabolism (Subcommittee on Physical Activity), in collaboration with the American association of Cardiovascular and Pulmonary Rehabilitation. Circulation 111(3): 369-376.

14. Madan K, Babu AS, Contractor A, Sawhney JPS, Prabhakaran D, et al. (2014) Cardiac rehabilitation in India. Progress in Cardiovascular Diseases 56(5): 543-550.

15. Defeo J (2017) Cardiac Rehabilitation. Increasing your patient's life expectancy. Lee's Summit Medical Center.

16. Hermes BM, Cardoso DM, Gomes TJ, Santos TD, Vicente MS, et al. (2015) Short-term inspiratory muscle training potentiates the benefits of aerobic and resistance training in patients undergoing CABG in phase II cardiac rehabilitation program. Rev Bras Cir Cardiovasc 30(4): 474-481.

17. Hughes AR (2003) Effect of an exercise consultation on maintenance of physical activity after completion of phase iii exercise based cardiac rehabilitation. Doctoral Thesis.

18. Noites A, Freitas CP, Pinto J, Melo C, Vieira Á, et al. (2017) Effects of a Phase IV Home-Based Cardiac Rehabilitation Program on Cardiorespiratory Fitness and Physical Activity. Heart Lung Circ 26(5): 455-462.

19. (1992) Recommendations by the Working Group on Cardiac Rehabilitation of the European Society of Cardiology. Long term comprehensive care of cardiac patients. Eur Heart J 13(Suppl C): 1C-45C.

20. Boulay P, Prud'homme D (2004) Health-care consumption and recurrent myocardial infarction after 1 year of conventional treatment versus short and long-term cardiac rehabilitation. Prev Med 38(5): 586-593.

21. Witt BJ, Jacobsen SJ, Weston SA, Killian JM, Meverden RA, Allison TG, et al. (2004) Cardiac rehabilitation after myocardial infarction in the community. J Am Coll Cardiol 44(5): 988-996.

22. Evenson KR, Fleury J (2000) Barriers to outpatient cardiac rehabilitation participation and adherence. J Cardiopulm Rehabil 20(4): 241-246.

23. Gallagher R, McKinley S, Dracup K (2003) Predictors of women's attendance at cardiac rehabilitation programs. Prog Cardiovasc Nurs 18(3): 121-126.

24. Farley RL, Wade TD, Birchmore L (2003) Factors influencing attendance at cardiac rehabilitation among coronary heart disease patients. Eur J Cardiovasc Nurs. 2(3): 205-212.

25. Randal JT (2015) The Gap in Cardiac Rehabilitation Referral: A System-Based Problem with System-Based Solutions. Journal of the American College of Cardiology 65(19): 2089-2090.

26. Scott LA, Ben-Or K, Allen JK (2002) Why are women missing from outpatient cardiac rehabilitation programs? A review of multilevel factors affecting referral, enrollment, and completion. J Womens Health 11(9): 773-791.

27. Grace SL, Gravely Witte S, Kayaniyil S, Brual J, Suskin N, et al. (2009) A multisite examination of sex differences in cardiac rehabilitation barriers by participation status. Journal of women's health 18(2): 209-216. 